\title{
Arlen D. Hanssen and W. Norman Scott (eds.): Total knee replacement + DVD
}

\author{
Saunders Elsevier, Philadelphia, 2009, 499 pp, number figures, Hardcover XXX US \$, \\ ISBN 978-1416049845
}

\author{
Pierre Kehr
}

Received: 28 February 2010 / Accepted: 1 March 2010 / Published online: 16 March 2010

(C) Springer-Verlag 2010

It is about a particularly interesting book taking again in an almost complete way all the surgical techniques of the arthroplasties of knee.

In a first part, the following are considered successively:

- the uni-compartimentary arthroplasty

- the postero-preserved and postero-stabilized tri-compartimentary arthroplasty

- the adjustment of the problems of rotation and alignment,

- the ligamentous balance and also the specific problems involved in the arthroplasties on genu valgum and genu varum

- the mini invasive surgery with its various initially possible ways (patellar para, sub-vastus, mid-vastus) is also studied

Lastly, a whole chapter is devoted to the characteristics of the no cemented and the cemented arthroplasties.

In a second part, the authors deal with problem of the revision surgery, describing successively the general principles, preoperative planning, the problem of the approach initially and the need for a good exposure with possible interest of a tibial clip and a plasty of the quadricipital tendon.

A chapter is devoted to the ligamentous balance in these revision arthroplasties, also on the risk on the level of the soft parts and the problems of the fixing of the implants with second surgeries.

Then, the specific problems of second surgeries after uni-compartimentary, tri-compartimentary prostheses are considered successively, problems of the second operations for sepsis, the problem of the losses of osseous substance,

P. Kehr $(\bowtie)$

SOTEST, Strasbourg, France

e-mail: kehrpier@aol.com with advantage of the tibial and femoral wedges, of the porous metaphysal cones (not very widespread in France), the problem of the massive autografts, finally of second part, are considered the complications such as the fractures on total knee prostheses, the arthrodesis and the ruptures of the quadricipital or patellar tendon, as well as the second operations on the level of the patella and the specific problem of the prostheses with hinges.

On the level of each various chapter of each part, the procedure is particularly detailed and extremely quite illustrated. The authors also give precise councils (style: tricks and easy ways). They also specify the instrumentation necessary. On the level of each chapter also, the various possible options are evoked, as well as the subjects of controversy or of discussion, the risks more particular to each technique, finally, the post-operative instructions are well specified.

It is necessary to underline the important iconography that accompanies each chapter: many photographs of great quality, explanatory sketches carried out particularly well with on the one hand anatomical recalls but also of the peroperational, extremely precise drawings.

The addition of a DVD taking again several of the chapters under consideration in the book very usefully comes to supplement this work.

On the whole, it is thus about a book particularly interesting, extremely complete taking again all the surgical techniques of knee arthroplasties with a remarkable iconography, which can make of it the "Bible" of the prosthetic surgery of the knee and which should be present in the library of each orthopaedic surgeon.

Pierre Herlin

Béthune (France)

No funds were received in support of this study. 